\title{
DESIDRATADAÇÃO DE CEBOLA UTILIZANDO UM SECADOR SOLAR CONVECTIVO DO TIPO BANDEJA
}

\author{
S. A. MIRANDA ${ }^{1}$, R. N. SILVA ${ }^{1}$, N.P. ALMEIDA ${ }^{1}$, K. G. SANTOS ${ }^{1^{*}}$ \\ ${ }^{1}$ Universidade Federal do Triângulo Mineiro, Departamento de Engenharia Química \\ *e-mail: kassiagsantos@gmail.com
}

\begin{abstract}
RESUMO
A insuficiência de energia nos dias atuais compromete a segurança alimentar, já que tem implicações diretas na preparação e conservação dos alimentos. A energia solar vem destacando por representar uma das fontes não poluente e inesgotável da Terra. Nesse sentido o trabalho propõe o aperfeiçoamento de um equipamento de secagem solar, construído por estudantes de Engenharia Química da UFTM, para a secagem de cebola. Foram realizados testes laboratoriais em infravermelho e estufa a fim de determinar as curvas de cinética de secagem da cebola, nas temperaturas de $60,80,100$ e $110{ }^{\circ} \mathrm{C}$. Realizou-se também a caracterização da partícula. Duas configurações do secados solar foram testadas e comparadas, realizando testes de secagem ao sol em duas condições, alta e baixa velocidade de rotação do cooler, sendo a temperatura monitorada a cada 30 minutos. Os resultados da configuração em que a bandeja encontra-se dentro do forno solar apresentou maior eficiência de secagem, principalmente na maior velocidade de rotação do cooler, que promove a convecção forçada.
\end{abstract}

\section{INTRODUÇÃO}

As frutas e os vegetais constituem fontes indispensáveis de nutrientes, vitaminas e minerais, exercendo assim um importante papel na nutrição humana. Eles possuem um alto teor de umidade, cerca de $80 \%$, com isso se tornam altamente perecíveis, necessitando de refrigeração ou processamento o mais rápido após a colheita (GAVA et al., 2008).

Uma das técnicas mais antigas na conservação de alimentos é a desidratação, que consiste na eliminação de água de um produto por evaporação, devido à transferência de calor e massa. No Brasil o método de desidratação mais comum, é por meio de secadores do tipo cabine com bandejas e circulação forçada de ar quente.
A secagem pode significar considerável economia no transporte, no manuseio e na estocagem do produto, além de aumentar a sua vida útil já que diminui a ação microbiana.

A carência de energia nos dias atuais compromete a segurança alimentar, já que tem implicações diretas na preparação e conservação dos alimentos, entre outras funções básicas diárias. Nesse sentido o sol se mostra como uma fonte de energia alternativa, podendo ser usado na desidratação de alimentos em secadores solares (IEHT,2009).

A cebola tem-se mostrado uma hortaliça que vem sendo bastante consumida na sua forma desidratada, principalmente por apresentar cerca de 86 a 92\% de água em sua 
composição, o que a torna altamente perecível Chemello (2005) apud Muniz (2007).

A secagem da cebola trata-se de uma atividade agroindustrial para a maior conservação da matéria-prima e, sobretudo para o aproveitamento da fração classificada como fora do padrão de comercialização. Inúmeras formulações de produtos, como os do tipo instantâneo, por exemplo, utilizam a cebola desidratada como ingrediente, sendo que esta também se apresenta para o consumidor como condimento de mesa (MARTINS e PINTO, 2003).

O objetivo deste trabalho é estudar a secagem solar de cebola, em um secador convectivo do tipo bandeja, empregando energia solar. Duas configurações do equipamento serão avaliadas, bem como o efeito do aumento da velocidade do ar sobre a taxa de secagem. A cinética de secagem e as características das partículas (forma, tamanho, densidade) também foram estudadas.

\section{METODOLOGIA}

\subsection{Caracterização das partículas}

As cebolas utilizadas na desidratação foram do tipo pera. Elas foram descascadas, devidamente higienizadas e cortadas em cubos uniformes com espessura de aproximadamente $0,5 \mathrm{~cm}$.

Para análise da forma das partículas de cebola, foi calculada a esfericidade, como sendo a relação entre a área superficial da esfera de mesmo volume que a partícula, e a área superficial da partícula. Para tal, separouse uma amostra do material e as dimensões das partículas foram aferidas com um paquímetro. A partir dessas mesmas medidas, foi obtido o diâmetro médio volumétrico de cada partícula da amostra, que é o diâmetro da esfera que tem o mesmo volume que a partícula. Com esses diâmetros, foram testados os diferentes Modelos de Distribuição Granulométrica, dentre eles os modelos GGS, RRB e Sigmóide. A densidade aparente das partículas foi obtida pela razão entre a massa e o volume de uma partícula de tamanho conhecido $(1,92 \times 1,9 \times 1,4 \mathrm{~cm})$, em triplicata.

\subsection{Cinética de secagem}

Foram realizados testes de laboratório no analisador de umidade infravermelho (marca GEHAKA, modelo IV 2500), para obter-se a cinética de secagem da cebola, bem como a difusividade média efetiva do material. $\mathrm{O}$ equipamento também conta com uma balança que permite a leitura direta da porcentagem de umidade perdida.

Os testes de cinética de secagem foram realizados nas temperaturas de $60,80,100 \mathrm{e}$ $110{ }^{\circ} \mathrm{C}$. A porcentagem de umidade perdida foi registrada inicialmente de 30 em 30 segundos, após de 1 em 1 minuto e posteriormente de 5 em 5 minutos até que a umidade da cebola atingisse o equilíbrio.

Para a determinação da razão de umidade, fez-se uso da seguinte relação:

$R U_{i}=\frac{X_{b s i}-X_{e}}{X_{b s 0}-X_{e}}$

em que $X_{b s i}$ é a umidade em base seca no instante (i), $X_{e}$ é a umidade de equilíbrio e $X_{b s 0}$ é a umidade em base seca inicial. Para determinação da umidade inicial e residual da cebola foram realizados testes em estufa, a $105^{\circ} \mathrm{C}$, por $24 \mathrm{~h}$

$\mathrm{Na}$ análise dos dados, foi adotada a hipótese de equilíbrio dinâmico, ou seja, no final do experimento, quando não mais se registra a perda de umidade da amostra, considera-se que a umidade residual está próxima à umidade de equilíbrio, assim $X_{e}$ foi considerada como sendo $90 \%$ da umidade final em base seca. Para o cálculo da taxa de secagem $(\mathrm{N})$ utilizou-se a Equação 2:

$$
N=\frac{\Delta R U}{\Delta t}
$$


em que $\Delta R U$ corresponde a variação da razão de umidade em cada instante e $\Delta t$ é a variação do tempo.

A partir dos dados de perda de massa das amostras durante a secagem nas diferentes temperaturas, foram testados algumas das equações que descrevem a cinética de secagem mais empregados na literatura, que estão disponíveis na Tabela 1 (COELHO, 2010; SOUZA, 2013). Os parâmetros cinéticos de cada modelo foram calculados, sendo escolhido o modelo que apresentou maior coeficiente de correlação quadrático.

$\mathrm{O}$ parâmetro $\mathrm{K}$, apresentado nestas equações da Tabela 1, é conhecido como constante de secagem e será empregado para determinar uma equação para a difusividade mássica efetiva, em função da temperatura, segundo a Equação 10.

$$
D_{e f}(T)=\left(L_{0} / \pi\right)^{2} \cdot K(T)
$$

\subsection{Unidades Experimentais}

\subsubsection{Configuração A}

A Figura 1-a) apresenta a Configuração A do secador solar, que é composto por: 1) o forno solar; 2) o secador representado; 3) o coletor solar. O forno solar possui dimensões de $1,5 \times 0,3 \times 0,3 \mathrm{~m}$ e foi construído com madeira MDF, revestido com papel alumínio e o seu fundo recoberto com placas de metal.

O secador foi construído com um tubo de PVC com $20 \mathrm{~cm}$ de diâmetro. $\mathrm{O}$ coletor solar foi construído com retalhos de espelhos e possui uma angulação de $60^{\circ}$. A coleta de ar pra dentro do forno é feita através de um cooler Marca Adda (6 W, $12 \mathrm{v}, 500 \mathrm{~mA})$, que promoveu a convecção forçada do ar de secagem.

Figura 1 - Secador solar convectivo do tipo bandeja: (a) Configuração A; (b) Configuração B.

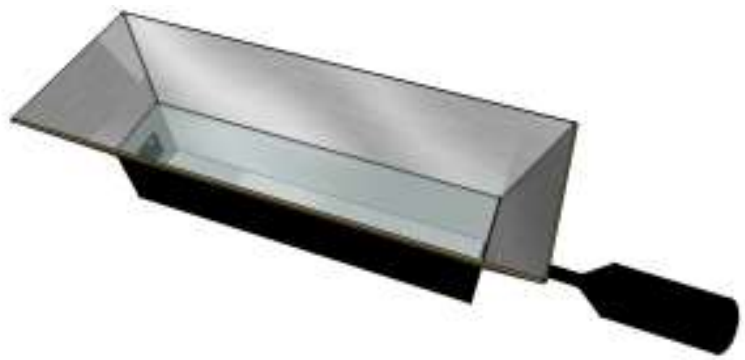

(a)

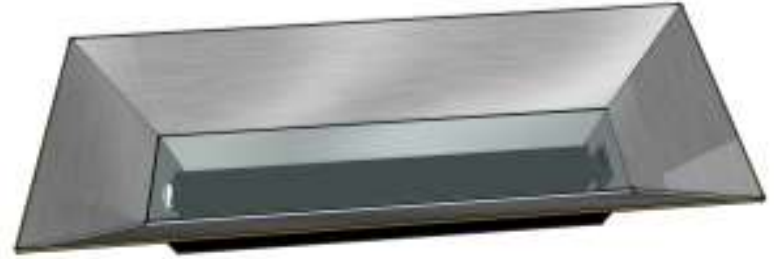

(b)

Fonte: Autor (2015)

Tabela 1 - Equações empíricas para ajuste de curvas de secagem.

\begin{tabular}{ll}
\hline Modelo & Equação \\
\hline Lewis (1921) & $R U=\exp [(-K t)], \operatorname{sendo} K=a \exp (-b / T f)$ \\
Brooker, et. al (1974) & $R U=c \exp [(-K t)], \operatorname{sendo} K=a \exp (-b / T f)$ \\
Henderson e Henderson (1968) & $R U=c \exp [(-K t)+1 / 9 \exp (-9 K t)], \operatorname{sendo} K=a \exp (-b / T f)$ \\
Page (1949) & $R U=\exp \left[\left(-K t^{n}\right)\right], \operatorname{sendo} K=a \exp (-b / T f)$ \\
Overhults et al (1973) & $R U=\exp \left[\left(-K t^{n}\right)\right], \operatorname{sendo} K=\exp (a+b / T f)$ \\
Midili & $R U=c \exp (-1(a \exp (-b / T)) K n)+d K$, sendo $K=(a \exp (-b / T))$ \\
Logarítmico & $R U=c \exp (-1(a \exp (-b / T)) K n)+d \operatorname{sendo} K=(a \exp (-b / T))$ \\
\hline
\end{tabular}

Fonte: (SOUZA, 2013) 


\subsubsection{Configuração B}

Na Configuração B do secador, o tubo de PVC que abrigava a bandeja foi substituído por uma calha de aço galvanizado que agora se encontra no interior do forno, como mostra a Figura 1-b).

A calha possui dimensões de $1,45 \mathrm{~m} \mathrm{x}$ $10 \mathrm{~cm} \times 7,5 \mathrm{~cm}$, foi devidamente higienizada e esterilizada com solução alcoólica $70 \%$ $(\mathrm{v} / \mathrm{v})$ e posteriormente pintada com tinta spray preta a fim de conservar o calor no forno por mais tempo.

\subsection{Experimentos de Secagem Solar}

Para realização dos experimentos pesou-se sempre uma massa fixa de aproximadamente $150 \mathrm{~g}$ de cebola cortada em cubos. $\mathrm{O}$ equipamento foi sempre posicionado onde havia maior captação de raios solares, e ao colocar o material a ser seco dentro do mesmo tomou-se as medidas de temperatura de 30 em 30 minutos por meio de um termômetro de mercúrio.

A fim de conduzir os testes de secagem empregando energia solar nas duas configurações de secador apresentadas, foi proposto um planejamento fatorial $2^{2}$, com duas variáveis qualitativas e dois níveis. $\mathrm{O}$ planejamento busca avaliar o efeito do tipo de configuração do secador e da rotação do cooler, sobre a eficiência de secagem, que pode ser avaliada pela razão de umidade do material produzido.

\section{RESULTADOS E DISCUSSÕES}

As partículas empregadas nos testes de secagem apresentaram uma densidade aparente de $0,975 \mathrm{~g} / \mathrm{cm}^{3}$.

A medida das partículas possibilitou o cálculo da esfericidade, que foi de 0,71 ; sendo que o que melhor representou a distribuição de tamanho das partículas foi o Modelo Sigmóide $\left(R^{2}=0,978\right)$, definido pela equação
(12), sendo que os parâmetros do modelo encontrados foram: $d_{50}=0,602 \mathrm{~cm}$ e $p=15,68$.

$$
X=1 /\left[1+\left(d_{50} / d_{v}\right)^{p}\right]
$$

\subsection{Cinética de secagem}

Estudou-se a cinética de secagem analisando-se a influência da temperatura na cinética de secagem da cebola. As curvas de secagem estão apresentadas na forma de razão de umidade em função do tempo e são mostradas na Figura 2.

Figura 2 - Curvas de secagem da cebola.

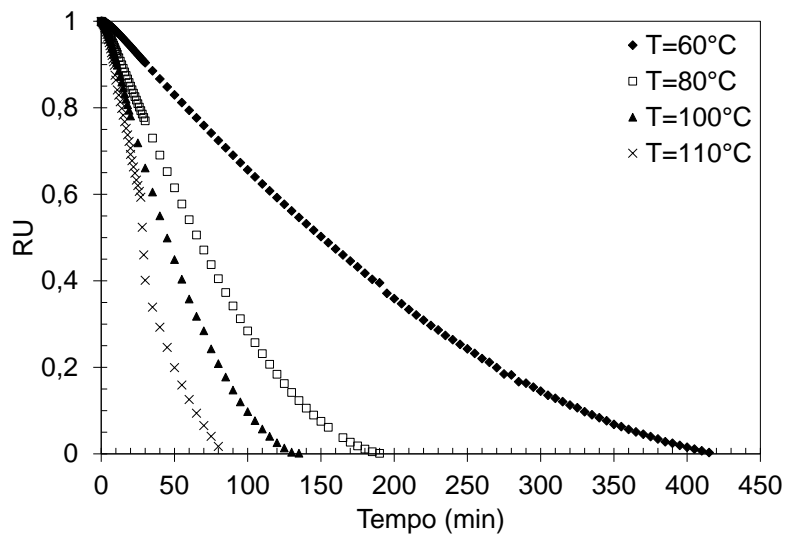

Fonte: Autor (2015).

Observa-se que a perda do teor de umidade é mais rápida no início do processo de secagem, pois há mais água livre na superfície para ser retirada. Percebe-se ainda, que a cinética de secagem foi fortemente influenciada pela temperatura, isto é, a secagem a uma temperatura mais elevada reduz expressivamente o tempo necessário para secar a cebola.

Analisando a curva da taxa de secagem em função da umidade em base seca para a temperatura de $60{ }^{\circ} \mathrm{C}$ (Figura 3), pode-se observar a presença de três períodos distintos da secagem: (a) aquecimento; (b) taxa constante; (c) taxa decrescente.

Os parâmetros dos ajustes das curvas de secagem empregando as equações empíricas da literatura são mostrados na Tabela 2. 
Figura 3 - Períodos de secagem para $60{ }^{\circ} \mathrm{C}$ Taxa de secagem em função da umidade em base úmida: (a) aquecimento do material; (b) taxa constante; (c) taxa decrescente (difusão e convecção).

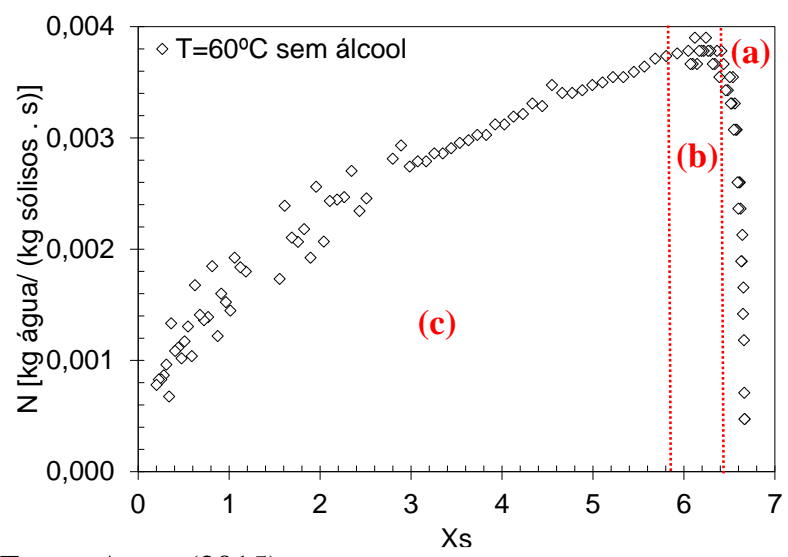

Fonte: Autor (2015).

Tabela 2 - Parâmetros cinéticos encontrados para os Modelos da Tabela 1.

\begin{tabular}{llrl}
\hline Modelo & \multicolumn{2}{l}{ Parâmetros } & \multicolumn{1}{l}{$\mathrm{R}^{2}$} \\
\hline \multirow{2}{*}{ Lewis } & $\mathrm{a}$ & 162,293 & \multirow{2}{*}{0,969} \\
& $\mathrm{~b}$ & 3419,943 & \\
\hline \multirow{3}{*}{ Benderson } & $\mathrm{c}$ & 0,995 & \\
& $\mathrm{a}$ & 161,470 & 0,967 \\
& $\mathrm{~b}$ & 3413,900 & \\
\hline \multirow{3}{*}{ Page } & $\mathrm{c}$ & 1,062 & \\
& $\mathrm{a}$ & 210,850 & 0,978 \\
& $\mathrm{~b}$ & 3481,511 & \\
Overhoots & $\mathrm{a}$ & 2785,128 & \\
& $\mathrm{~b}$ & 5024,969 & 0,992 \\
& $\mathrm{n}$ & 1,378 & \\
\hline \multirow{4}{*}{ Midilli } & $\mathrm{a}$ & 5,75 & \\
& $\mathrm{~b}$ & $-3645,54$ & 0,992 \\
& $\mathrm{n}$ & 1,38 & \\
& $\mathrm{c}$ & 0,991 & \\
& $\mathrm{a}$ & 3860,375 & \\
\hline Logarítmico & $\mathrm{b}$ & 5165,072 & 0,992 \\
& $\mathrm{n}$ & 1,382 & \\
& $\mathrm{~d}$ & 0,000 & \\
& $\mathrm{c}$ & 1,083 & \\
& $\mathrm{a}$ & 1221,765 & \\
& $\mathrm{~b}$ & 4635,470 & 0,993 \\
& $\mathrm{n}$ & 1,280 & \\
\hline & $\mathrm{d}$ & $-0,085$ & \\
\hline
\end{tabular}

Nota-se que o modelo que melhor ajustou os dados experimentais de perda de umidade da cebola foi o Modelo Logarítmico, pois este apresentou o melhor coeficiente de correlação quadrática $\left(R^{2}=0,993\right)$.

Para o cálculo da difusividade efetiva utilizou-se a Equação 10 (SOUZA, 2013), considerando $L_{0}$ como a metade da espessura do sólido, que no caso da cebola é aproximadamente $0,12 \mathrm{~cm}$, e o modelo Logarítmico que é o que melhor se ajustou, tem-se o valor de $D_{e f}\left(\mathrm{~cm}^{2} / \mathrm{s}\right)$ em função da temperatura $(\mathrm{K})$, como mostra a equação 12 , em que $L_{0}$ é a metade da espessura em centímetros e o parâmetro cinético a tem unidade de $\mathrm{s}^{-1}$.

$D_{e f}=3,578 \exp \left(\frac{-4635,47}{T}\right)$

\subsection{Secagem Convectiva com Energia Solar}

Nesta etapa, foram realizados inicialmente 4 experimentos definidos pelo planejamento fatorial $2^{2}$. No qual buscou-se avaliar o efeito da configuração do secador (Configurações A e B) e da rotação do cooler (maior e menor), sobre a razão de umidade final obtida, bem como a umidade residual em base seca. Os resultados obtidos estão disponíveis na Tabela 3.

Pode-se observar que os testes realizados na configuração A (experimentos 1 e 2) apresentaram umidade residual muito elevada, frente aos valores obtidos pela nova configuração proposta (configuração B).

A Figura 4 mostra o aspecto da cebola seca em cada experimento do planejamento fatorial, onde observa-se que a desidratação foi bem mais efetiva na nova configuração de secador proposta.

As variações de temperatura com o passar do tempo para cada experimento são mostradas na Figura 5. Vale ressaltar que a temperatura da secagem é dependente das condições climáticas, não sendo possível controlar seu valor neste tipo de experimento. No entanto, todos os experimentos foram realizados em dias ensolarados, com poucas nuvens. 
Tabela 3 - Dados experimentais para as diferentes condições avaliadas.

\begin{tabular}{|c|c|c|c|c|}
\hline \multicolumn{3}{|c|}{ Variáveis (codificação) } & \multicolumn{2}{|c|}{ Respostas } \\
\hline Experimento & $\begin{array}{l}\text { Equipamento } \\
\qquad\left(\mathrm{x}_{1}\right)\end{array}$ & $\begin{array}{l}\text { Rotação } \\
\left(\mathrm{x}_{2}\right)\end{array}$ & $\begin{array}{c}\text { Xs } \\
{\left[\begin{array}{l}\mathrm{kg} \text { de água } \\
\text { kg de sólido }\end{array}\right]}\end{array}$ & RU \\
\hline 1 & $\mathrm{~A}(-1)$ & Baixa $(-1)$ & 5,13 & 0,4740 \\
\hline 2 & $\mathrm{~A}(-1)$ & $\operatorname{Alta}(+1)$ & 3,72 & 0,3280 \\
\hline 3 & $\mathrm{~B}(+1)$ & Baixa $(-1)$ & 0,30 & 0,0130 \\
\hline 4 & $\mathrm{~B}(+1)$ & Alta $(+1)$ & 0,23 & 0,0045 \\
\hline 5 & A $(-1)$ & $\begin{array}{l}\text { Baixa }(-1) \\
2 \text { bandejas }\end{array}$ & 1,28 & 0,0932 \\
\hline
\end{tabular}

Fonte: Autor (2015).

Figura 4 - Aspecto final da cebola após cada experimento: (a) Exp. 1; (b) Exp. 2; (c) Exp. 3; (d) Exp. 4.

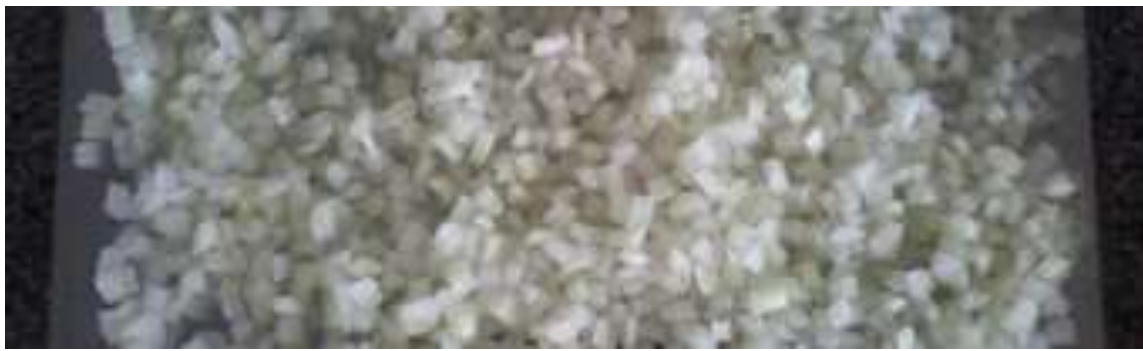

(a)

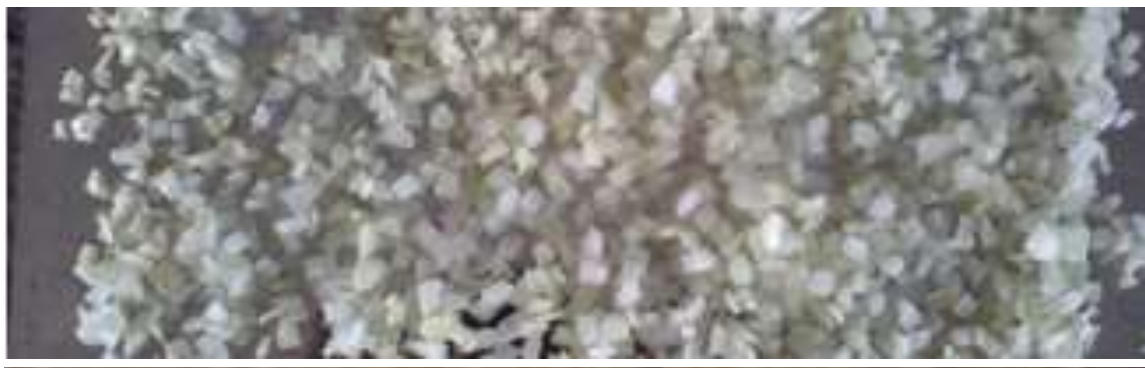

(b)

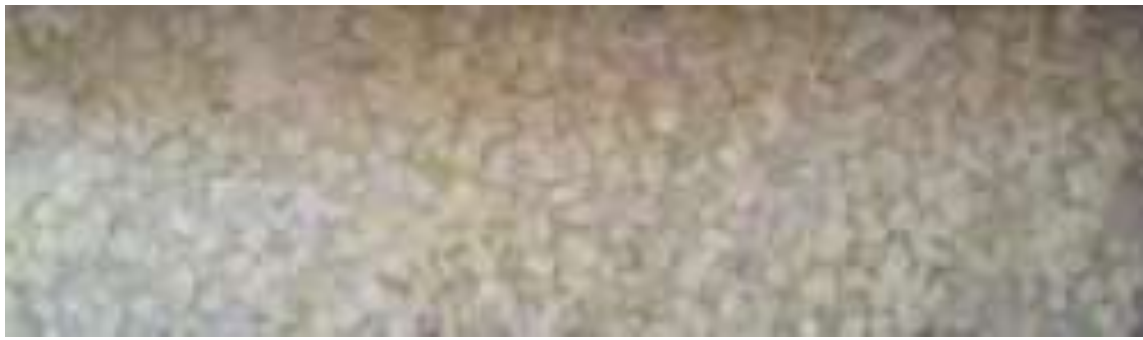

(c)

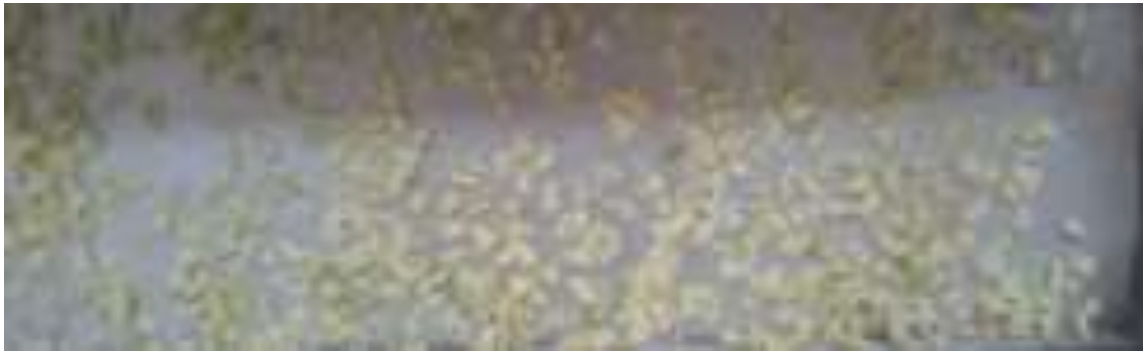

Fonte: Autor (2015). 
Figura 5 - Gráfico com as variações de temperatura com o passar do tempo nas diferentes condições experimentais (todos os dias foram ensolarados, com poucas nuvens).

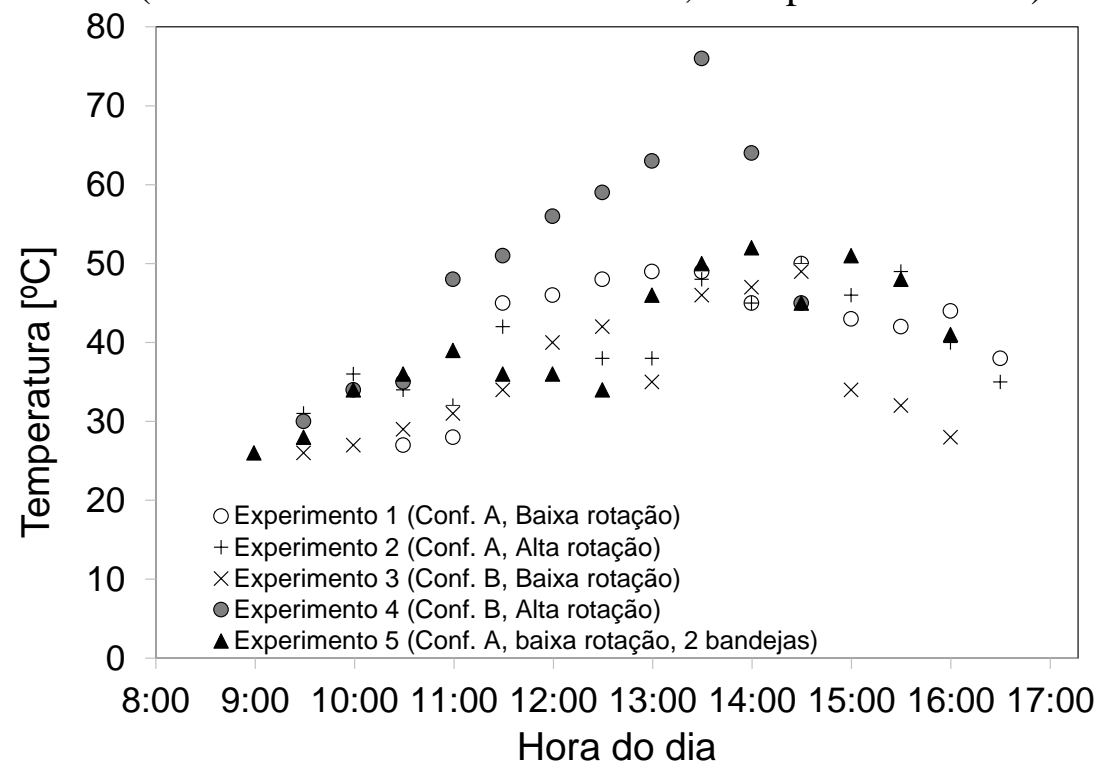

Fonte: Autor (2015).

Observando as curvas de temperatura do ar de secagem, nota-se que os picos de temperatura geralmente ocorreram por volta das 12:00 e 13:00 horas, que é o momento em que o sol incide diretamente sobre o coletor. Em alguns casos, ocorreram desvios inesperados de temperatura, que podem ter sido causados pela diminuição da temperatura ambiente pela presença de correntes de ar próximas do aparato; de nuvens que impediam a incidência solar e pela chuva que impediu na continuidade do experimento.

Nota-se ainda que nem todos os experimentos começaram no mesmo horário e tiveram a mesma duração, o que também se deu devido as condições climáticas. O ideal seria repetir os experimentos nas mesmas condições e duração. Porém, pelo fato dos testes terem sido realizados no verão, que é uma época que possui grande incidência solar, e ao mesmo tempo altas precipitações, se torna mais difícil a realização de muitos experimentos e nas mesmas condições.

A fim de avaliar o efeito das variáveis estudadas sobre a umidade final da cebola, optou-se pela metodologia estatística utilizando a técnica de superfície de resposta. Foi realizada uma análise de múltipla regressão, sendo os parâmetros estimados por mínimos quadrados, com um nível de significância do teste de $10 \%$. A análise de variância da regressão foi apresentada através do teste de $\mathrm{F}$ e do coeficiente de correlação $\mathrm{R}^{2}$.

A Tabela 4 representa os resultados da regressão para a razão de umidade removida durante a secagem.

Tabela 4 - Efeitos das variáveis sobre a razão de umidade residual ao fim da secagem $\left(\mathrm{R}^{2}=0,973\right)$.

\begin{tabular}{lccc}
\hline Fator & Parâmetro & Desvio & $\begin{array}{c}\text { Nível de } \\
\text { Significância }\end{array}$ \\
\hline Média & 0,2037 & 0,0335 & 0,1033 \\
$x_{1}$ & $-0,1949$ & 0,0333 & 0,1079 \\
$x_{2}$ & $-0,0376$ & 0,0333 & 0,4619 \\
$x_{1} x_{2}$ & 0,0333 & - & $>0,4600$ \\
\hline
\end{tabular}

Fonte: Autor (2015). 
Observa-se que o tipo de secador é que exerce o maior efeito sobre a razão de umidade. O sinal negativo do coeficiente mostra que no maior nível da variável 1 (Configuração B) é que se atinge os menores valores de RU ao fim do experimento. $\mathrm{O}$ mesmo pode ser afirmado para a rotação do cooler, sendo que o aumento desta também diminui a razão de umidade no fim do experimento, mostrando que esta condição favorece a secagem, como era esperado, pois maiores rotações do cooler conduzem a maiores velocidades de ar, o que aumenta a perda de umidade por convecção. As mesmas conclusões podem ser obtidas através da análise da superfície de resposta para a razão de umidade (RU), disposta na Figura 6.

Figura 6 - Superfície de resposta para a razão de umidade em função do tipo de secador e rotação do cooler (variáveis codificadas).

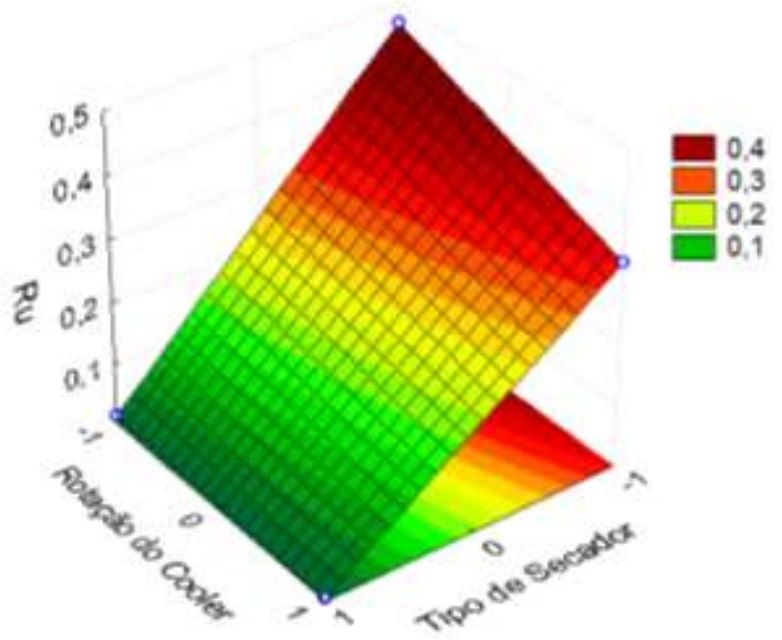

Fonte: Autor (2015).

No momento da realização dos experimentos com a configuração original (A), percebeu-se que usando apenas uma bandeja formava-se uma camada muito espessa de cebola, o que pode ter dificultado a passagem do ar sobre o material, influenciando negativamente na eficiência de secagem do mesmo. A fim de verificar essa hipótese realizou-se um novo experimento, com baixa velocidade de rotação do cooler e duas bandejas, denominado Exp. 5, com resultado disponível na Tabela 3.

Ao comparar os resultados do experimento $1 \mathrm{com}$ o do experimento 5 (com 2 bandejas), nota-se uma melhora na eficiência de secagem, que pode ser atribuída a melhor distribuição do material sobre as bandejas. No entanto, a secagem realizada no secador com configuração B ainda se mostrou mais eficiente.

Esse resultado encontrado na nova configuração do equipamento pode ser explicado pela introdução da calha e das placas de metal no interior do forno. A calha é feita de aço galvanizado que é um bom condutor de calor, com isso o ar aquecido permanece no forno por mais tempo, possibilitando atingir maiores temperaturas e também pelo fato do secador agora estar dentro do forno o ar perde menos calor, passando mais aquecido pelo material. As placas no interior do forno também ajudam a manter o ar aquecido por mais tempo.

De modo geral pode-se dizer que as alterações feitas no equipamento de secagem, proporcionaram significativa melhoria na eficiência do aparato. Quanto ao produto final não se pode comparar as umidades residuais obtidas com as descritas na literatura, pelo fato de não ter sido especificado se a mesma estava em base úmida ou base seca.

Entretanto, ao observar o aspecto final da cebola desidratada na melhor condição, nota-se que ela apresentou visualmente as características desejadas um aspecto folheado. Acredita-se que a cebola desidratada possa ter atingido as condições exigidas, mas para afirmar isso com certeza, outros tipos de analises devem ser realizadas, como por exemplo, analises sensoriais, microbiológicas, físico-químicas entre outras. 


\section{CONCLUSÕES}

Pela análise das curvas de secagem pode-se perceber que a temperatura influência significativamente na taxa de secagem, ou seja, quanto maior a temperatura menor é o tempo gasto para a desidratação da cebola, entretanto temperaturas.

Quanto a melhor configuração do equipamento, pode-se afirmar que o secador do tipo B, foi mais eficiente, já em todas as condições apresentou melhores resultados em relação à umidade final da cebola e as maiores temperaturas foram atingidas nesse equipamento.

Já quanto a melhor rotação do cooler não se pode dizer qual a melhor, uma vez que variando a mesma não se obteve mudanças significativas quanto à umidade final do produto. Portanto, não pode-se dizer qual a melhor condição operacional apenas qual a variável mais significativa, que neste caso foi a configuração do forno.

De modo geral pode-se dizer que os objetivos propostos no trabalho foram alcançados, uma vez que conseguiu-se otimizar a eficiência do equipamento já existente, e apesar de não ter disso possível a comparação da umidade residual do teste experimental com o da literatura, chegou-se a resultados visualmente satisfatórios quanto a característica final da cebola.

\section{NOMENCLATURA}

\begin{tabular}{|c|c|}
\hline$a, b, c, d, n:$ & $\begin{array}{l}\text { Parâmetros dos } \\
\text { cinéticos de secagem }\end{array}$ \\
\hline$D_{e f}:$ & $\begin{array}{l}\text { Difusividade Efetiva em função } \\
\text { da temperatura }\end{array}$ \\
\hline$d_{v}:$ & $\begin{array}{l}\text { Diâmetro da esfera de igual } \\
\text { volume que a partícula }\end{array}$ \\
\hline$d_{50}:$ & 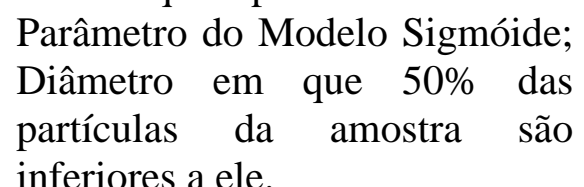 \\
\hline
\end{tabular}

$K(T)$ : Constante de secagem em função da temperatura

$L_{0}$ : $\quad$ Metade da espessura da partícula

$N: \quad$ Taxa de secagem

$p: \quad$ Parâmetro do Modelo Sigmóide

RU: $\quad$ Razão de Umidade

$t: \quad$ Tempo

$T: \quad$ Temperatura

$X: \quad$ Fração mássica acumulativa

$X_{b s i}: \quad$ Umidade em base seca no instante (i).

$X_{e}: \quad$ Umidade de equilíbrio dinâmico

$X_{b s 0}: \quad$ Umidade em base seca inicial

$x_{1} ; x_{2}: \quad$ Variáveis codificadas

\section{REFERÊNCIAS}

COELHO, K. D. Secagem de tomate (lycorpesiconesculentummill) em camada delgada: avaliação das características físico-químicas. 2010. 97p. Dissertação (Mestrado em Engenharia de Alimentos). Universidade Federal do Rio Grande, Rio Grande, 2010.

GAVA, A. J., SILVA, C. A. B.; FRIAS, J. R. G. Tecnologia de alimentos: princípios e aplicações. São Paulo: Nobel, 2008, 512 p.

IEHT: Instituto de Estudios del Hambre. Tecnologias. Sociais para a Segurança Alimentar, 2009.

MARTINS, P. C; PINTO, L. A. A. Caracterização da Secagem de Cebola (Allium cepa L.) em Camada Delgada e da Reidratação do Produto Desidratado. Braz. J. Food Technol., v.6, p.143-151, 2003.

MUNIZ，L. B. Caracterização química, física e de compostos funcionais em cebolas frescas e minimamente processadas. 2007. 160p. Dissertação (Mestrado em Nutrição 
Humana). - Universidade de Brasília, Brasília, 2007.

SOUZA, G. F. M.V. Secagem de sementes de soja em leito fixo: equilíbrio e cinética da sílica gel para controle de umidade, modelagem do processo e análise da qualidade das sementes. 2013. 157p. Tese (Doutorado em Engenharia Mecânica) Universidade Federal de Uberlândia, Uberlândia, 2013.

\section{AGRADECIMENTOS}

Os autores agradecem à UFTM pela Bolsa de Auxílio à Permanência (PROACE) e ao CNPq pela Bolsa PIBIC de Iniciação Científica. 